\title{
Jóvenes en la política partidaria Una aproximación a las organizaciones de juventud, vinculadas a los partidos políticos en Colombia ${ }^{*}$
}

\author{
a) \\ Gladys Lucia Acosta V. \\ Recibido: 15 de agosto \\ Aprobado: 17 de noviembre
}

\section{Resumen}

Frente al discurso que pregona la supuesta apatía y desafección de los jóvenes por la política partidaria, este ensayo se propone relativizar dicho supuesto, a partir de un acercamiento a las formas de participación de los jóvenes en las organizaciones y colectivos de juventud, vinculados a los partidos y movimientos políticos en Colombia.

Las organizaciones de juventud, adscritas a los partidos y movimientos políticos en Colombia, si bien -con pocas excepciones- están lejos de inaugurar modos de participación que puedan considerarse propiamente juveniles, sí constituyen escenarios que propician la formación ideológica y el fortalecimiento -o cuando menos la conservación- de las prácticas y de las rutinas que han hecho tradición en la dinámica partidaria. En el marco de las conclusiones es propio afirmar que, no obstante las limitaciones y las precariedades que exhiben las organizaciones de juventud, vinculadas a los partidos políticos en Colombia, su existencia constituye un punto de apoyo a la supervivencia y por qué no a la revitalización y afinación de los partidos políticos que en sociedades complejas como las nuestras, mientras no existan otras instituciones que los superen o sustituyan, los partidos políticos son instituciones necesarias para profundizar la democracia.

Palabras clave: participación política, organizaciones de juventud partidaria; modalidades de participación.

* Este ensayo es un producto de la investigación Prácticas de participación política desde las cuales los y las jóvenes constituyen ciudadanías juveniles en Medellín, realizada en convenio entre la Universidad de Medellín y la Corporación de Producción Audiovisual Platohedro.

** Licenciada en Español y Literatura y Magíster en Docencia de la Universidad de Antioquia. Coautora del libro Construcción de Identidad y Función Política en el Discurso del Director de Comunicaciones. Compiladora-editora, junto con Luis Alfonso Ramírez Peña, del libro Estudios del Discurso en Colombia. Autora de diversos artículos sobre análisis del discurso. Actualmente es docente-investigadora en la Universidad de Medellín, en la categoría de asociada e integrante del grupo de investigación Comunicación, Organización y Política. Correo electrónico: gacosta@udem.edu.co 


\title{
The Youth in Party Politics An Approach to Youth Organizations Involved in Colombian Political Parties
}

\begin{abstract}
With respect to the speech promoted by a presumable apathy and disaffection of young people for the politics of parties, this essay is intended to give such assumption a relative sense from an approach to the ways of participation young people use in youth organizations and groups involved in political parties and movements in Colombia.

Youth organizations involved in political parties and movements in Colombia (with few exceptions) are away from creating ways of participation which can be deemed as juvenile themselves; they do are scenarios which promote ideological training and strengthening (or conservation at least) of practices and routines which have been a tradition in the dynamic of political parties. With respect to conclusions, it should be noticed that, despite the limitations and scarcity exhibited by youth organizations involved in political parties in Colombia, their existence constitutes a point of support for survival and maybe revitalization and improvement of political parties which are institutions necessary for practicing democracy in depth, when there are no better institutions to replace them in societies as complex as the Colombian one.
\end{abstract}

Key words: political participation; party youth organizations; ways of participation. 


\section{Introducción}

En el marco de las reflexiones y de los análisis sobre la participación en política partidaria, fundamentalmente en la población juvenil, se ha convertido en un lugar común señalar que la precaria participación de los jóvenes en las dinámicas partidarias (bien sea en torno al sufragio o bien a la membresía o activismo en los partidos o en los movimientos políticos) obedece a la desconfianza -más o menos generalizada- de la ciudadanía en general o de los jóvenes en particular frente a los partidos políticos; se arguye -además- que esa desconfianza se justifica por múltiples razones, entre ellas: promesas incumplidas, incapacidad de estas colectividades para representar los intereses y canalizar las demandas sociales; prácticas clientelistas; corrupción; vinculación con grupos al margen de la ley, entre otras.

De otro lado, en el ámbito de los estudios de juventud, se suele esbozar como razones de la apatía o la desafección de los jóvenes por la política, la lejanía existente entre las prácticas y las rutinas que caracterizan la dinámica partidaria y las sensibilidades y prácticas juveniles que según algunos estudiosos (Valenzuela, 2007; Urresti, 2000; Reguillo 2000; Botero y Torres 2008) están más cerca del arte, la estética y la cultura.

No se puede negar que los argumentos que se esgrimen tienen la fuerza de los hechos a su favor, sin embargo, hay una razón de tipo ideológico que suele permanecer oculta, pero que explicaría la apatía de la ciudadanía en general y de la población juvenil en particular por la política partidaria. Se trata -en definitiva- de un argumento que- sin desconocer la existencia de los desvíos propios de los partidos y de la clase política, en generalreconoce que dicha apatía es el producto de la estrategia que promueven los grupos económicos de orientación neoliberal y que aplican y celebran los gobernantes, muchas veces resguardados bajo la sombrilla de la modernización del Estado.

El interés en incrementar la imagen negativa y la condición de crisis que se le atribuye a los partidos políticos e incluso la proclamación de su muerte se acompaña de una exaltación de los personalismos políticos; de la promoción de una supuesta democracia participativa y de un Estado comunitario; del incremento del individualismo; del recorte del Estado, mediante procesos de privatización, y de la liberación de la economía de los controles del Estado. Estos intereses, propios del neoliberalismo, tienen mejores frutos cuando se ejercen en sociedades individualistas en las que no hay modos de canalizar las demandas y los problemas sociales; en sociedades que han privilegiado las lógicas de lo privado en detrimento de lo público y lo político.

En el trasfondo de estos y otros argumentos, que intentan caracterizar al joven de esta época, así como sus modos de participación y acción política, está la imagen unificada y cristalizada de un sujeto joven que, o bien ha sido construido por los estudiosos de la juventud, o bien por los discursos hegemónicos y desmovilizadores, que intentan desvirtuar las vías políticas mediante una exacerbación de la crisis de los escenarios de representación y de la expansión de un discurso que pregona la apatía y desafección de los jóvenes por la política partidaria.

En este contexto, en la investigación "Modalidades de participación política desde las cuales los y las jóvenes construyen ciudadanías en Medellín", nos inclinamos a decir que la participación juvenil, al igual que la participación de cualquier actor social, suele adscribirse en unos ámbitos o esferas de actuación en la vida social; ejercerse en una pluralidad de escenarios (lugares de relación e interacción); orientarse desde una gama de finalidades (visiones y horizontes de acción e interacción); responder a unos determinados propósitos (macro-temas o asuntos que los convoca); y, actualizarse en una pluralidad de modalidades (maneras o modos que caracterizan una intervención, en atención tanto a las características y a las opciones de los grupos o colectivos juveniles, como a las condiciones de los escenarios, las finalidades y los propósitos que los convocan).

En el marco de la multiplicidad de ámbitos y de escenarios (Acosta y Garcés, 2010) por los 
que discurre la participación juvenil, este artículo se propone el análisis de uno de los escenarios trabajados en la investigación y, de manera puntual, en el ámbito de la política instituida; se trata del escenario que se configura desde los partidos políticos y, de manera puntual, desde las organizaciones de juventud partidaria.

De modo que este artículo se orienta a caracterizar la participación de los jóvenes en organizaciones de juventud política y partidaria. Sin embargo, previo a la caracterización de los modos de inserción o de apropiación por parte de los jóvenes de estos escenarios, es preciso analizar el contexto político. Dicho análisis comprende, en primer lugar, la descripción de los partidos y sus funciones en el escenario político; en segundo lugar, una breve caracterización de lo que ha sido la dinámica partidaria en Colombia; $\mathrm{y}$, finalmente, un análisis de la coyuntura política que marca la primera década del presente siglo.

\section{Análisis del contexto: el papel de los partidos en el escenario político}

Para una mayor comprensión de lo que son los partidos políticos, sus dinámicas en el marco de los regímenes políticos y en las modalidades de Estado, las funciones sociales e institucionales que cumplen, las crisis que enfrentan y los retos que deben asumir, se acude al estudio realizado por Cárdenas (2001). El autor empieza por definir los partidos como una agrupación con ánimo de permanencia temporal que media entre los grupos de la sociedad y el Estado, al tiempo que participa en la lucha por el poder político y en la formación de la voluntad política del pueblo, principalmente a partir de los procesos electorales.

Así entendidos, resulta claro vislumbrar el por qué los partidos son los principales actores del escenario político y los constructores de los regímenes democráticos, dado que -tal y como lo sostiene Cárdenas- en el Estado moderno, los partidos cumplen con una serie de funciones y de tareas de tipos social e institucional. Entre las primeras se tienen: socialización política (en relación con la responsabilidad de educar a los ciudadanos en la de- mocracia); movilización de la opinión pública (posibilitan espacios para la expresión y la confrontación de ideas y de sentires, al tiempo que buscan su concreción eficaz); representación de intereses (son medios para encauzar los intereses de las comunidades, privilegiando aquellos que resulten más cercanos a su origen histórico e ideológico); legitimación del sistema político (por el rol que juegan en la conformación de los órganos del Estado; porque son escenarios de debate y confrontación están obligados a fortalecer los procedimientos y las instituciones democráticas).

En lo que respecta a las tareas de orden institucional, los partidos deben atender: a el reclutamiento y la selección de élites o grupos dirigentes que puedan ocuparse de los asuntos públicos; influir en la elaboración de la legislación electoral en todas sus etapas; según los resultados de los comicios electorales, integrar las corporaciones del poder legislativo, o bien, desde la oposición, ejercer el control y velar por el cumplimiento de las responsabilidades de quienes ostentan el poder.

En el contexto de estas condiciones y características que les son propias a los partidos políticos y que trazan sus rutas de prácticas en la arena política, podría quedar cuando menos la sensación de que lo expuesto no hace otra cosa que ofrecer una imagen idealizada de lo que son los partidos políticos. Pero como ocurre con toda congregación de actores sociales, una cosa suelen ser las vías trazadas desde los ideales humanos y otra lo que ocurre en la complejidad de los contextos en los que los partidos se configuran, se consolidan y actúan.

De hecho, en las sociedades contemporáneas que comparten regímenes democráticos, las dinámicas partidistas están atravesadas por una serie de situaciones que -en su conjunto y pese a la diversidad de sus manifestaciones- han terminado consolidando lo que algunos denominan "crisis de representación". Dicha crisis obedece a factores tales como:

- Debilidad de la función socializadora que les es propia y que se expresa en la incapacidad 
de los partidos para vincularse con las aspiraciones, los intereses y las demandas de la sociedad;

- El auge de los movimientos sociales que por sus condiciones de origen y su capacidad de articular las demandas y los intereses de las comunidades, así como de movilizar la opinión pública han rebasado a los partidos;

- La utilización de vías de reclutamiento de elites distintas a los procedimientos democráticos internos que terminan generando un funcionamiento oligárquico de los partidos;

- Los modelos racionales de política que han hecho perder el interés de los ciudadanos por los asuntos políticos;

- Frente a la muerte de las grandes ideologías que pretendían explicarlo todo, la política y los partidos han perdido el interés y su capacidad para congregar voluntades.

Frente a este panorama, que los detractores de los partidos políticos suelen exacerbar hasta llegar a concluir que asistimos al fin de los partidos políticos, Cárdenas (2001) plantea una pregunta que resulta bastante reveladora: ¿Podrán los partidos sortear la crisis $y$, de ser así, cuál es su futuro?

Por supuesto que la respuesta no es única y, en su lugar, encierra enorme complejidad, pues, la respuesta a este interrogante involucra, necesariamente, el análisis de factores medulares a las prácticas partidarias como lo son las condiciones particulares que definen los regímenes políticos (democrático o no democrático) de las distintas naciones y el tipo de sociedad (homogénea o heterogénea).

A la luz de los planteamientos que recogemos de Cárdenas y, de manera particular, retomando el carácter reivindicatorio que le confiere el autor a los partidos políticos como instancias definitivas en la formación, consolidación o profundización de la democracia, surge una inquietud -que bien podría considerarse como punto de partida para reflexiones futuras- en cuanto a la crisis de los partidos y la necesidad de revitalizarlos: ¿A quiénes o a qué le resulta rentable o beneficioso declararles la muerte a las vías políticas en general y a los partidos políticos en particular?

Una condición que, muy probablemente por razones de orientación y de perspectiva, no toca Cárdenas en lo que respecta a la crisis de los partidos y al uso que de sus falencias hacen sus detractores es que la crisis de los partidos y el anhelo de que lleguen a su fin tiene que ver con la expansión del discurso neoliberal y la promoción e idealización de las prácticas de gestión privadas, que se asumen como un ejemplo a seguir para el manejo de la cosa pública. Esta exaltación del paradigma privado y el manejo de los asuntos del Estado bajo la lógica del mercado terminan por invalidar y satanizar las vías políticas, entre ellas las que les son propias a los partidos políticos.

La proclamación de la muerte de los partidos, el descrédito de la política y la invocación a la democracia directa pueden ser las estrategias que más convienen a los populismos de izquierda y de derecha, a las corrientes totalitarias y autoritarias; pero tal y como lo afirma Cárdenas, en sociedades complejas como las nuestras, los partidos polí ticos -mientras no existan otras organizaciones que los superen o los sustituyan- son una necesidad para una competencia democrática por el poder; para una formación de los ciudadanos en la vida democrática; para encauzar, mediante los mecanismos legítimos, las necesidades e insatisfacciones de los colectivos sociales.

Esta consideración no le resta importancia a la necesidad de que los partidos actualicen sus prácticas, consoliden sus procesos democráticos, repiensen permanentemente sus funciones sociales y constitucionales, y rectifiquen sus rutas de acción; todo ello con el propósito de que cumplan con las funciones y las tareas que el momento histórico les impone. 


\subsection{Una aproximación a los partidos políticos en Colombia}

En el propósito de contextuar la dinámica partidaria en Colombia, se acude al trabajo de Duque $(2007,2)$ en el que se logra una síntesis de las condiciones sui géneris del sistema bipartidista en Colombia. Afirma el autor que los actores predominantes en la política partidaria han sido el Liberal y el Conservador que, desde sus orígenes, han marcado la historia política colombiana, bien con su presencia e interacción competitiva con períodos de hegemonías gubernamentales: conservadora entre 1878-1930; liberales 19301946; de nuevo, conservadora 1946-1953); de violencia partidista (década del 40 hasta comienzos del 60); de quiebres democráticos, generado por sus confrontaciones (durante el gobierno de Rojas Pinilla); acuerdos y coaliciones (en el Frente Nacional).

Agrega el citado autor que solo en la década del 30, es decir, bajo el dominio liberal se conforma la primera fuerza de oposición organizada, después de los intentos fallidos de los movimientos socialistas, el Partido Comunista que, con diversas dinámicas organizativas, se amplía hasta la década del 60 hasta confluir, en los años 90, en una segregación de fuerzas que dan origen al Polo Democrático.

Ahora bien, el carácter sui géneris del bipartidismo en Colombia lo explica Duque (2007: 16), acudiendo a la tipología que establece Sartori (1994: 195), cuando, afirma que se trata de un bipartidismo de fachada, dado que, si bien los dos partidos muestran continuidad en el tiempo, al lado de precarias e inestables terceras fuerzas, exhiben una débil institucionalización, producto de la fragmentación o división interna, el fuerte personalismo y el predominio de los parlamentarios. De hecho, en el ámbito nacional predominan las fracciones en torno a jefes que logran aglutinar apoyos regionales de parlamentarios, diputados, concejales y otros políticos locales. En el ámbito subnacional, las facciones, en cabeza de los congresistas y, en algunos casos de exgobernadores y diputados departamentales, funcionan con base en micro-organizaciones que constituyen pequeñas maquinarias políticas.

No obstante, como lo advierte Giraldo (2003: 35 ; 36) con la reforma impulsada por la Asamblea Nacional Constituyente, ANC y con la promulgación de la carta política de 91 se establecen nuevas reglas que amplían los espacios de acción y de participación política, al tiempo que elevan a rango constitucional los partidos y movimientos políticos tradicionales y emergentes, por medio de la institucionalización, la penalización del clientelismo, el fortalecimiento de la democracia participativa y el reconocimiento del pluralismo; el proceso de democratización está todavía abierto. Esto es así dado que, a la par de los contenidos y las rutas propuestas en la carta constitucional, que arroja como resultado la ampliación del espectro político (con la inclusión de nuevas fuerzas políticas, particularmente las indígenas), los partidos tradicionales buscan acomodar sus antiguas prácticas, a partir de propuestas de cambios constitucionales que, en últimas, lo que están produciendo es la atomización de los partidos mediante coaliciones precarias con fines electorales que han terminado por incrementar el clientelismo y las prácticas de manipulación en el sistema político. En este contexto, tal y como afirma Giraldo (2003; 36) En el clientelismo actual se intercambian favores y bienes por votos, se incrementan los costos de las campañas electorales y se conforman las denominadas micro-empresas electorales.

En lo atinente a las prácticas clientelistas, Roll (2002; 60-77) sostiene que el clientelismo es uno de los factores determinantes de la crisis de los partidos políticos y en su análisis de este fenómeno sostiene que lo más preocupante es que el clientelismo en Colombia no solo es un factor más de política, sino el articulador mismo del sistema político. Con miras a explicar los alcances de este fenómeno, el citado autor acude a varias definiciones del clientelismo; entre ellas nos parece afortunada -por su amplitud- la definición propuesta por Díaz Uribe (1986; 19) citado por Roll, en la que se reconoce a este fenómeno 
como el conjunto de relaciones de intercambio de prestaciones y contraprestaciones entre quienes a falta de recursos, garantizan su fidelidad política a terceros debido a su poder político, económico o social. Si bien, en un sentido moderno el clientelismo es la herencia del Frente Nacional, en las prácticas políticas actuales persisten algunos rasgos del clientelismo tradicional que le precede a este período histórico, entre ellos, el caciquismo o el patronazgo.

Sin embargo, como lo reconoce Roll (2002; 68) el hecho de que el clientelismo actual dependa de la utilización de los recursos oficiales es lo que lo hace sustancialmente diferente de otros modos de actualización. En este sentido, en las áreas deprimidas, el caciquismo ha sufrido la forma del clientelismo, pero este opera tanto en estratos bajos como en altos; en estos, por ejemplo, las empresas contratistas que son beneficiadas con las licitaciones públicas agradecen a los partidos con importante apoyo económico para las campañas electorales.

Si bien con la Constitución del 91 se intentó frenar el clientelismo, la habilidad de los políticos ha sido superior a esta intención, tal y como lo evidencian las prácticas que se actualizan para hacer el quite a las restricciones establecidas en la Carta Constitucional.

\subsection{El contexto de coyuntura (primera década del siglo XXI)}

En el marco de la construcción del contexto de la política partidaria en Colombia es importante acotar, así sea de manera panorámica, los acontecimientos de coyuntura que abarcan la primera década del siglo XXI y que inician con un fenómeno político: el ascenso al poder de Álvaro Uribe Vélez. Este abandera el proyecto de "La Seguridad Democrática", proyecto que logra aglutinar los intereses de las elites colombianas en torno a la recuperación del poder del Estado en lucha frontal contra un enemigo único, las FARC, EP. Este interés por lo que acontece en el período 2002-2010 obedece a las implicaciones que, para la vida de los partidos y de los movimientos políticos en Colombia, ha tenido la denominada "era del uribismo".

\subsubsection{Los partidos políticos en la era Uribe}

En el año 2001, Álvaro Uribe Vélez, militante del partido Liberal Colombiano, regresa de Londres y anuncia que competirá con Horacio Serpa la consulta del partido, para la elección del candidato único a la presidencia para el período 2002-2006. Sin embargo, bajo el argumento de falta de garantías, Uribe Vélez renuncia a la colectividad y se lanza como independiente con el respaldo del movimiento ciudadano "Primero Colombia" con el que logra la presidencia en la primera vuelta.

Este primer período alimentó y fortificó un gobierno caudillista a costa de un debilitamiento de los partidos políticos y de lo que podría denominarse una estocada final al bipartidismo en Colombia; de igual forma, fue el abono para el florecimiento de partidos políticos de fácil cooptación mediante la estrategia del clientelismo, utilizada también para cooptar a los partidos más tradicionales - caso concreto del partido Conservador- del cual logra debilitar su ideología. De esta manera, en el año 2006, el mismo movimiento, es decir, Primero Colombia - que había permanecido inactivo, resurge para apoyar la primera reelección.

La reelección que -hasta el ascenso de Uribe Vélez- no estaba contemplada en la Constitución constituye, al pensar de algunos críticos y estudiosos de la política colombiana, un atentado contra la institucionalidad y un acontecimiento que, al juzgar por las revelaciones sobre los actos de corrupción que comprometen el gobierno Uribe, fue el abono con el que se alimentó el clientelismo y la corrupción.

A continuación se presenta una pequeña reseña de los movimientos y partidos que han ayudado a consolidar lo que hoy día se denomina el Uribismo. 


\section{Colombia Democrática'}

Colombia Democrática tiene su origen en 1985 como un movimiento de disidencia del Directorio Liberal de Antioquia, encabezado por el entonces senador Álvaro Uribe Vélez, su primo Mario Uribe Escobar y otros líderes antioqueños, quienes argumentaban diferencias ideológicas con respecto al partido Liberal Colombiano. Uno de los pilares de este movimiento es el fortalecimiento de una democracia participativa -origen y fundamento de lo que en el gobierno de Uribe se postulará como Estado Comunitario o Estado de Opiniónbajo el presupuesto de que el departamento de Antioquia y el País en general requerían fortalecer la democracia. El movimiento logró el apoyo de dirigentes y líderes liberales de Antioquia, lo que permitió triunfos en los distintos órganos de representación regional y local que culminaron con el nombramiento al senado de Mario Uribe en el 2000 y con la elección del presidente Uribe en el 2002. En el 2003 se inscribe como partido ante el Consejo Nacional Electoral con el nombre de Partido Colombia Democrática.

El escándalo de la parapolítica teje un manto de duda sobre el partido, pues, un alto número de sentadores están siendo investigados e incluso muchos de sus miembros han sido condenados. La falta de representación en las corporaciones conllevó a la pérdida de la personería jurídica de este partido.

\section{Partido Social de Unidad Nacional (Partido de la $U)^{2}$}

Organización política que se forma en torno a la figura del Presidente Álvaro Uribe Vélez, bajo el supuesto de que la derrota definitiva del terrorismo requería la unión de todos las fuerzas en torno a la figura de un líder carismático de firmes convicciones, que prometía la entereza para

1 Reconstrucción de lo que aparece en la página Web del partido. http://www.colombiademocratica.com/index. php?option $=$ com_contentEtask $=$ viewEid $=17$ Eltemid $=31$

2 La información de base es tomada de: http://www.partidocambioradical.org/nosotros.html combatir el terrorismo. De este modo, previo a la aprobación de la Reforma Política de 2003, se logra una coalición de congresistas representantes de distintas fuerzas partidistas (conservadores, sectores del liberalismo, Colombia Democrática y Cambio Radical) en torno al Presidente y a su política de "Seguridad Democrática" a fin de constituir el Nuevo Partido, que luego da origen al partido de la $U$.

La fuerza de este nuevo partido se refleja en los resultados de las elecciones para corporaciones del 2006 en las que obtuvo un alto número de curules para Senado (20) y Cámara (33). Sin embargo, el mayor logro del partido se da en la contienda electoral que culmina con la reelección del presidente Álvaro Uribe.

Tras el fallo de la Corte Constitucional que declara inexequible la convocatoria a un referendo para aprobar la segunda reelección del presidente Uribe, la fuerza del partido de la U se aglutina en torno a la figura de Juan Manuel Santos.

\section{Cambio Radical $^{3}$}

En el marco de la convención liberal en la que se iba a elegir a Horacio Serpa como candidato a la presidencia por el liberalismo, celebrada en enero de 1998, un grupo de disidentes, argumentando que las altas esferas del partido liberal habían permitido la infiltración del narcotráfico, realizan su propia convención en la que se adopta una plataforma de reivindicaciones populares y en donde se asume el reto de construir nuevas formas de hacer política. En el mismo año se toma la decisión de apoyar la candidatura a la presidencia del exfiscal general Alfonso Valdivieso, sin embargo, frente a la renuncia del candidato, esta fuerza disidente del liberalismo decide apoyar al candidato por el partido conservador Andrés Pastrana. En el año 2000, este movimiento político toma el nombre de Cambio Radical; en el año 2001, mediante consulta interna a los asambleístas, se decide apoyar

3 La información de base es tomada de la página Web: http://www.elpartidodelau.com/index.php?p=3Eite= 1 
al candidato Álvaro Uribe Vélez, quien alcanza, en primera vuelta, la presidencia con una mayoría abrumadora.

Con base en los resultados obtenidos por el movimiento en el año 2002 (5 senadores y 10 representantes) a lo que se aúna el triunfo del Candidato que el movimiento apoyó, se tramita -frente al Consejo Nacional Electoral - el cambio de movimiento a partido político. En elecciones posteriores el partido ha logrado engrosar su capital político. En el año 2006, Cambio Radical hace parte de la coalición uribista para la primera reelección. En el año 2009 -frente al acontecimiento político que marcó la agenda en el País: el referendo para la aprobación de la segunda Reelección del Presidente Uribe (2010-2014) - el partido, que se había configurado como un fuerte aliado del uribismo, toma distancia con respecto a la propuesta de una segunda reelección del Presidente y se lanza a la contienda electoral con candidato propio.

El Partido Conservador hizo parte de la coalición que llevó al poder a Uribe Vélez y apoyó la reelección para el período 2006-2010; así como el proyecto que aspiraba a la segunda reelección. El Partido Liberal -en su condición de constitución pluralista se dividió entre oficialistas, opositores del proyecto de Uribe Vélez; opositores radicales -la corriente que abandera Piedad Córdoba, y los "Uribistas" que terminaron migrando a los partidos abiertamente declarados uribistas, es decir, el Partido de La U y Cambio Radical. . El Polo Democrático, por su parte, permaneció en la oposición y desempeñó una función bien importante en el campo del control político.

\subsubsection{Consideraciones en términos de la coyuntura política}

Dos características, al parecer, son las que resultan dominantes en la definición de lo que algunos han denominado la era Uribe; ellas son: personalismo y fortalecimiento de un liderazgo carismático que logró, por una lado, una fuerte concentración del poder; y por otro, el debilita- miento de los dos partidos políticos de mayor tradición y que por mucho tiempo compartieron los escenarios del poder representativo en el País: el partido Liberal Colombiano y el Partido Conservador.

El debilitamiento del bipartidismo en Colombia y la explosión de movimientos o de partidos -que emergen particularmente en coyunturas electorales- podría considerarse un avance en términos de pluralismo ideológico y programático. Sin embargo, las características precarias e inestables de estas fuerzas -que al parecer son más fragmentaciones amañadas de una misma orientación ideológica (pugnan por los puestos de poder y luego se disuelven) que formación de verdaderos espacios de representación y de lucha política y programática- refuerzan la convicción de que no hay una apuesta por el fortalecimiento de los escenarios de representación sino su utilización con fines personalistas.

Si se agrega a lo anterior que, no existen diferencias sustantivas entre una y otra fuerza y por esta razón no se puede hablar de pluralismo ideológico, pues, incluso estas fuerzas -al igual que los partidos de mayor tradición (Partido Liberal Colombiano y Partido Conservador)- han perdido o cuando menos desdibujado su orientación ideológica, en este sentido, la mayoría de estas fuerzas buscan identificarse o mejor ser reconocidas como "fuerzas de centro" y evitarán ser definidos como partidos de derecha o de izquierda.

En este contexto, vale la pena traer a colación uno de los postulados clave de la propuesta teórica de Mouffe (1999; 2007), el pluralismo agonístico. Interpretando a la autora, se puede afirmar que una democracia radical supone siempre la existencia de un pluralismo agonístico, en donde los partidos políticos -en lugar de limitarse a la representación de sus propios intereses- le apues tan a la presentación de proyectos alternativos de sociedad o de país. El carácter alternativo de tales proyectos compromete la definición de las fronteras políticas e ideológicas que diferencian la izquierda de la derecha. De este modo, la lucha 
por el poder en las contiendas electorales se hace en términos del apoyo con el voto a un proyecto político en el interior de una oferta de proyectos; los ciudadanos tienen la opción de escoger entre propuestas claramente diferenciadas e incluso irreconciliables. El proyecto que resulte ganador se erige como fuerza hegemónica, pero su poder estará siempre amenazado por otras fuerzas que pugnan -en el terreno de los mecanismos democráticos- por alcanzar el poder.

Pero en Colombia, particularmente en los 8 años del gobierno Uribe, se acuñó lo que bien podría denominarse una satanización de las vías políticas frente a una exaltación de las lógicas privadas para la gestión de lo público. En este sentido, hay que decir que el discurso gubernamental se empeñó, por una parte, en descalificar los partidos políticos y, en general, los espacios o vías de representación política, al tiempo que se promulgaba la idea de una "democracia o un Estado de opinión"; en segundo lugar, por desdibujar y desvirtuar las fronteras políticas entre izquierdas y derechas. Este empeño se vio fortalecido por la figura carismática del líder que con el refuerzo permanente de los medios de comunicación logró el fortalecimiento de la imagen de redentor y, por lo tanto, una fe ciega en la figura presidencial.

\section{Las organizaciones de juventud partidaria}

El surgimiento y la consolidación de las organizaciones de juventud partidaria obedecen a razones de distinta índole, todas ellas ancladas, bien a las necesidades y requerimientos propios o inherentes a los partidos y movimientos políticos o, bien, a las demandas y a los retos que el momento histórico les hace a éstos. En cualquier caso, al parecer, el origen de estas organizaciones se produce al margen de los deseos, las aspiraciones o las necesidades de las organizaciones, los colectivos o los grupos juveniles.

En síntesis, las organizaciones de juventud partidaria surgen por decisión del partido que frente a la normativa (Constitución del 91; Ley de
Juventud o ley 375), las tendencias mundiales (reconocimiento de derechos; multi y pluri culturalidad; inclusión, etc.), las condiciones socio-políticas del País (pérdida de credibilidad de la ciudadanía en las fuerzas partidarias; supuesta apatía política generalizada; emergencia de colectivos o movimientos de resistencia civil; triunfo electoral de líderes carismáticos, respaldados por movimientos ciudadanos; el privilegio de gobernantes y de la ciudadanía a mecanismo propios de la democracia directa), sus propias necesidades y requerimientos (resultados precarios en comicios electorales; necesidad de incrementar el número de militantes; formación de líderes para la renovación; recuperar la confianza de la ciudadanía, etc) optan por convocar distintos grupos poblacionales, entre ellos: mujeres y jóvenes.

A continuación se presenta una breve descripción de las cuatro organizaciones de juventud partidaria que fueron objeto de estudio, ellas son: Juventudes liberales, Renovación Conservadora; Polo Joven; Jóvenes Verdes de Colombia. Posterior a la descripción de las organizaciones o colectivos, se presenta la tabla (Prácticas de participación política en las organizaciones y colectivos de juventud partidaria) que recoge dos elementos clave de la matriz de observación y de análisis de las organizaciones, asuntos que congregan a los jóvenes, y modalidades de participación.

\section{1 Juventudes Liberales}

La creación de las "Juventudes Liberales" se da en el 2000 cuando el partido, con la creación de la Ley Nacional de Juventud, sintió que era necesario generar en interior un espacio para la población juvenil (en esto tuvo mucho que ver la participación y elección de los jóvenes en las elecciones de CMJ de los municipios más importantes del país como Medellín y Bogotá). "Poder Joven" es el sector de juventudes del Movimiento Liberal "Poder Ciudadano Siglo XXI" que abandera la exsenadora Piedad Córdoba, movimiento que surge como un modo de resistencia civil a la elección de César Gaviria como Presidente del partido Liberal Colombiano. 


\subsection{Renovación Conservadora}

Aunque en el Partido Conservador han existido diversos movimientos que agrupan a la población juvenil, como los Comandos Juveniles en la época de Jota Mario Valderrama o las Juventudes Conservadoras, hasta el 2001 nunca se había creado -desde la dirección del partido ni por los estatutos del mismo- un grupo que congregara a los jóvenes entre los 14 y los 30 años, cuando el partido realizó el proceso de democratización interna en la Convención Conservadora de ese mismo año y en la cual se pretendía "repensar el partido" buscar hacerlo más participativo y por ello también se decidió implementar el mecanismo de votación popular para la elección de las mesas directivas nacionales, departamentales y municipales. A pesar de que "Nuevas Generaciones" surgió en el 2001, su actividad real comienza en el 2005, pues en los cuatro años que comprendió este período los jóvenes que participaron eran en su mayoría hijos de "caciques" políticos que los nombraban a dedo y los hacían participar de las actividades del partido sin que ellos tuviesen interés alguno en hacer parte de él. Sólo hasta el 2005 se logró comenzar un proceso de fortalecimiento de Nuevas Generaciones con jóvenes que ingresaban al partido y al grupo por voluntad propia y con la convicción de trabajar por él.

\subsection{Polo Joven}

Su constitución formal se da en el Primer Congreso Nacional del Polo Democrático Independiente en 1999. Allí se plantea la división del partido por grupos poblacionales, entre ellos los jóvenes, atendiendo también a la necesidad de crear cultura y participación política en la población juvenil en Colombia. Desde su creación el trabajo de Polo Joven ha sido constante y sin interrupciones; con reuniones quincenales o mensuales según las necesidades; actualmente cumple 10 años de creación que se celebraron con el Primer Congreso Nacional de Polo Joven que se realizó en Ibagué en el mes de febrero.

\subsection{Jóvenes Verdes de Colombia}

El partido Verde Opción Centro se constituye a finales de 2005, bajo la personería jurídica del antiguo partido Alianza $\mathrm{M}-19$, pues, no contaba con el porcentaje de votos requeridos, según normativa del 2003. En el 2008, se unen al partido tres exalcaldes de Bogotá (Antanas Mockus, Luis Eduardo Garzón y Enrique Peñaloza). El mismo año, en la celebración del congreso extraordinario, el partido queda bajo la codirección de los tres exalcaldes. Posteriormente, y mediante consulta popular, fue elegido como candidato a la presidencia por el partido a Antanas Mockus. En el caso de los jóvenes verdes de Colombia en general y, en Antioquia en particular, se constituye un "gran colectivo". En este sentido, su conformación y funcionamiento son flexibles y espontáneas; dependen más del compromiso y la euforia individual que se contagia a otros, hasta tejer redes en pro-de la propuesta del candidato Mockus que de la pertenencia a una estructura organizativa.

\section{Consideraciones generales en torno a las organizaciones de juventud partidaria}

En los enunciados con los que cada una de las organizaciones o colectivos expresa lo que la define están las huellas de las enunciaciones (postulados, principios, valores) propias del partido o movimiento político al cual está adscrita la organización de juventudes. De este modo, se pueden reconocer en los enunciados, los énfasis ideológicos e incluso programáticos que igual sirven para diferenciar un partido de otro.

- "Convicciones y principios democráticos" (Juventudes Liberales)

- Estamos convencidos de que Colombia requiere de un rumbo distinto para alcanzar un futuro próspero: una democracia real; una sociedad civil empoderada y vigilante; un modelo económico con más corazón; una globalización que respete la posibilidad de 
todos los pueblos a decidir su futuro; etc (Poder Joven).

- $\quad$ "La unidad nacional; respeto a la ley; fortalecimiento de las instituciones". (Renovación del partido Conservador)

- $\quad$ "Posibilidades de construcción conjunta de la izquierda"; reconocimiento y respeto de los derechos humanos; paz y solidaridad; defensa de lo público y desmilitarización del país." (Polo Joven)

- "Desarrollo económico, no violencia; sostenibilidad; sabiduría ecológica; manejo transparente y eficiente de los recursos públicos." (Jóvenes verdes de Colombia)

De esta condición es posible inferir, en primer lugar, la apropiación de los postulados y principios doctrinales que han hecho los jóvenes de estas organizaciones; situación que -de ser así- constituiría un garante para la preservación e incluso fortalecimiento de los partidos políticos, tal y como se conocen hoy. En segundo lugar, las organizaciones o colectivos de juventudes, más allá de intervenir para transformar las dinámicas que caracterizan, para bien o para mal, a los partidos políticos, tienden a preservar y / o a reproducir las voces que ellos mismos están legitimando. En tercer lugar, llama la atención la similitud de apuestas que, aparentemente, son fruto de ideologías completamente diferentes; es el caso de "Poder Joven" cuya modalidad de enunciación es más cercana al Polo Joven y a Jóvenes Verdes de Colombia que a Juventudes Liberales.

Sin embargo, las diferencias entre los postulados, los principios y los valores de las organizaciones de Juventud son -en general- muy sutiles y más de forma que de contenido, tanto como lo son las diferencias entre los partidos y movimientos políticos, a los que estas organizaciones están vinculadas. Dicho en otros términos, los partidos políticos en Colombia no portan grandes diferencias y, en ocasiones, aquellos que se adscriben a corrientes liberales resultan defendiendo postulados y principios más conservadores que los mismos Conservadores. Esta consideración podría tomarse como un punto de partida cuando se trata de repensar el sentido de una democracia representativa que se erige en torno a las dinámicas partidistas y a las diferencias programáticas que se ponen en juego en la lucha por el poder político. Si no hay diferencias entre las apuestas políticas de los partidos, ¿por qué se vota por X o Y partido? ¿Qué es lo que convoca el apoyo ciudadano?

De otro lado, un punto que resulta interesante analizar es el de consignas, eslóganes, o logo-símbolos, pues, estos enunciados -generalmente cortos y con efectos sintácticos y fonológicos que ayudan a la recordación- cumplen una función bien importante en el marco de las contiendas electorales. Las consignas, además, sirven para sintetizar las posturas ideológicas con las que nos identificamos. Asimismo, estas expresan un alto contenido emotivo; es, en definitiva un cuerpo de enunciación que busca un cuerpo que lo exprese y lo encarne. En el caso del colectivo de Jóvenes Verdes de Colombia, las consignas -además de su contenido político- llevaban una alta carga energética cultural y simbólica que, sin lugar a dudas, tuvo un efecto detonador para los y las jóvenes. De este modo se puede explicar por qué, a pesar de que el Partido Verde expresaba una cercanía o cuando menos simpatía con la continuidad de una política de Seguridad Democrática, la fuerza que imprimió el colectivo de jóvenes insinuaba un cambio en la manera de hacer, de sentir y de experimentar la política. Se trataba en definitiva de una puesta en escena del lenguaje que es un híbrido entre cultura y política.

"A mí no me pagaron, yo vine porque quise"; "Levanten el lápiz los que están con Antanas, Yo estoy con Antanas, la vida es sagrada."

Asimismo, el caso del colectivo "fuerza joven", adscrito a Juventudes Liberales, y, particularmente el logo símbolo que lo representa "Ser 
joven es ser revolucionario", refuerza lo que se afirmaba en términos de romper con lo que es prototípico o aquello que se espera como enunciado posible y predecible de una organización adscrita al partido Liberal.

\section{Prácticas de participación política de los jóvenes en las organizaciones partidarias}

Para dar cuenta de las prácticas de participación juvenil que involucran, por un lado, la defini- ción de los temas o asuntos que convocan a los jóvenes vinculados a las organizaciones partidarias, por otro lado, la identificación y la descripción de lo que hacen y de los modos en que lo hacen, se acude a una tabla (prácticas de participación) en la que se presenta lo que le es propio a cada organización o colectivo de juventud. Los datos que se ofrecen son reconstrucciones de las voces de los y las jóvenes entrevistadas; así como de la información que se suministra en las páginas y en los grupos que se crean y que circulan en Facebook.

Tabla Prácticas de participación política de las organizaciones y colectivos de juventud partidaria

\begin{tabular}{|c|c|c|}
\hline $\begin{array}{c}\text { Organización o } \\
\text { colectivo }\end{array}$ & Asuntos que los congrega & Actividades y modalidades de participación \\
\hline $\begin{array}{l}\text { Juventudes } \\
\text { Liberales }\end{array}$ & $\begin{array}{l}\text { Ideología del partido: Discutir acer- } \\
\text { ca de los planteamientos internos } \\
\text { de la colectividad, reflexionar en } \\
\text { torno a ellos y hacer propuestas } \\
\text { para su mejoramiento que se trans- } \\
\text { mitan posteriormente a instancias } \\
\text { superiores. } \\
\text { Coyuntura política nacional: Se dis- } \\
\text { cuten temas que versan sobre as- } \\
\text { pectos que afectan a la población } \\
\text { juvenil en el país y que después del } \\
\text { debate se convierten en proyectos } \\
\text { de acuerdo que los representantes } \\
\text { que hacen parte de Juventudes Li- } \\
\text { berales le presentan a Concejales } \\
\text { municipales y diputados departa- } \\
\text { mentales para que promuevan su } \\
\text { aprobación en cada uno de los es- } \\
\text { pacios a los que tienen acceso. } \\
\text { Planeación, organización y/o apoyo } \\
\text { a actividades específicas: encuen- } \\
\text { tros académicos, acompañamien- } \\
\text { tos a marchas, pronunciamientos, } \\
\text { etc. }\end{array}$ & $\begin{array}{l}\text { SESIONES DE DISCUSIÓN: Son convocadas por los coordina- } \\
\text { dores departamentales y según establecen los estatutos deben } \\
\text { ser -mínimo- cada } 20 \text { días calendario. En ellas se abordan temas } \\
\text { concernientes a la ideología política del partido y se desarrollan } \\
\text { también discusiones acerca de coyunturas nacionales e interna- } \\
\text { cionales. } \\
\text { SESIONES DE FORMACIÓN: Para los } 26 \text { representantes elegidos } \\
\text { por votación popular y que tratan temáticas como liderazgo y } \\
\text { desarrollo social. } \\
\text { FOROS ACADÉMICOS: Que tratan temas de interés público y } \\
\text { con acceso libre a todos los ciudadanos, por ejemplo foros so- } \\
\text { bre problemática de la población LGTB en Medellín, entre otros. } \\
\text { CREACIÓN DE GRUPOS Y PÁGINAS EN REDES SOCIALES; blog } \\
\text { y periódico virtual "la Calle" para construir opinión, convocar a } \\
\text { eventos e interactuar. } \\
\text { PARTICIPACIÓN Y/O CONVOCATORIA A MANIFESTACIONES PÚ- } \\
\text { BLICAS: vinculación a marchas y/O manifestaciones que vayan } \\
\text { en consonancia con los principios del partido y con los intereses } \\
\text { particulares de Juventudes Liberales de Antioquia. } \\
\text { FOROS SUBREGIONALES: Se realizan } 2 \text { foros por cada subregión } \\
\text { del departamento que buscan hacer formación política y para el } \\
\text { liderazgo de los jóvenes de dichos lugares. } \\
\text { Activa participación de los integrantes en otras instancias políti- } \\
\text { cas de la ciudad (CMI) } \\
\text { (están en proceso de aprobación y creación de una secretaría } \\
\text { - en liderazgo }\end{array}$ \\
\hline
\end{tabular}




\begin{tabular}{|c|c|c|}
\hline $\begin{array}{c}\text { Organización o } \\
\text { colectivo }\end{array}$ & Asuntos que los congrega & Actividades y modalidades de participación \\
\hline $\begin{array}{l}\text { Nuevas } \\
\text { Generaciones } \\
\text { Partido } \\
\text { Conservador }\end{array}$ & $\begin{array}{l}\text { La discusión de asuntos políticos, } \\
\text { económicos, sociales y de actuali- } \\
\text { dad del país. } \\
\text { Tratamiento de temas que permi- } \\
\text { tan el fortalecimiento del partido. } \\
\text { La realización de actividades de ca- } \\
\text { pacitación y formación política. } \\
\text { Realización de actividades sociales } \\
\text { (brigadas de salud, entre otros tra- } \\
\text { bajo sociales). } \\
\text { El tema de género ha tomado fuer- } \\
\text { za en el partido. } \\
\text { Las contiendas electorales para } \\
\text { corporaciones regionales y nacio- } \\
\text { nales son las que más convocan a } \\
\text { la participación. }\end{array}$ & 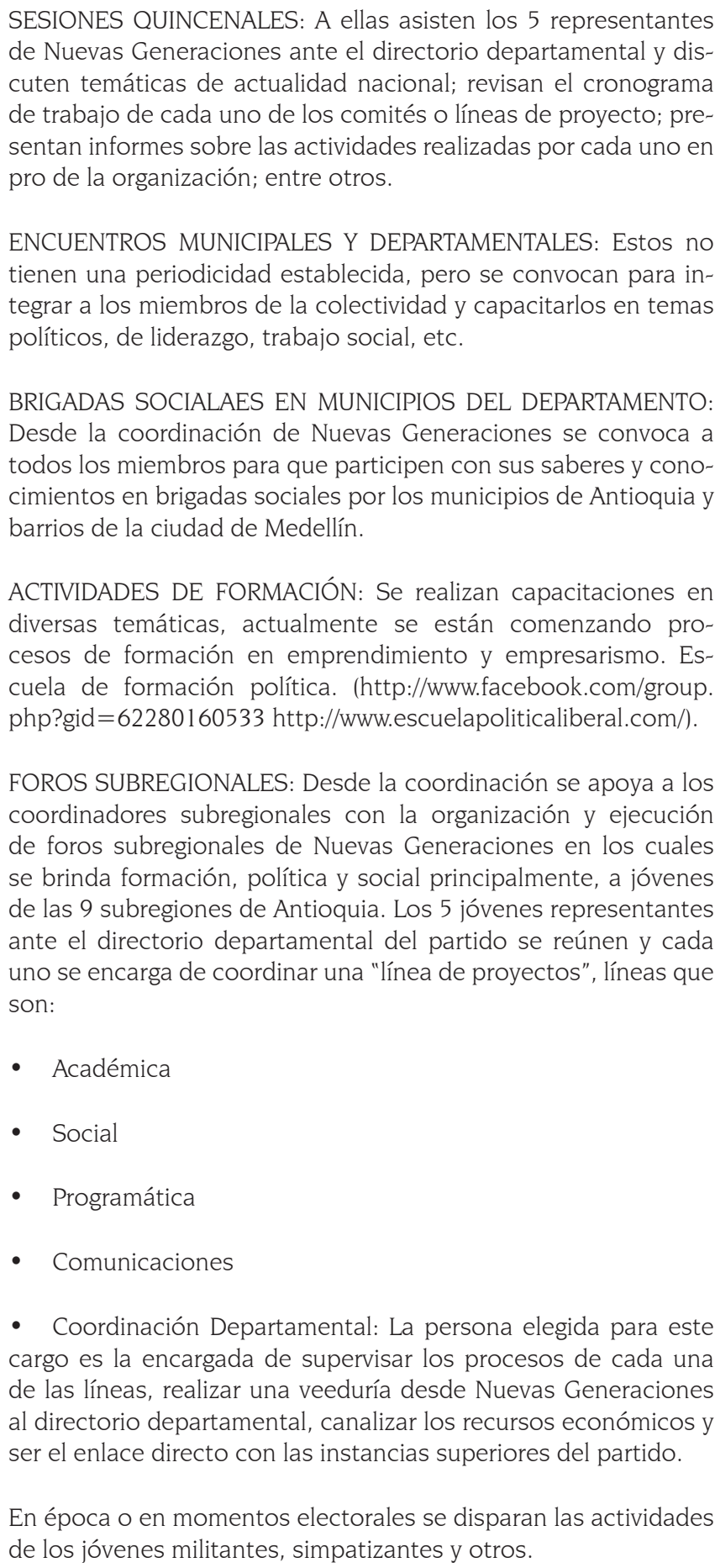 \\
\hline
\end{tabular}


Jóvenes en la política partidaria. Una aproximación a las organizaciones de juventud, vinculadas a los partidos políticos en Colombia

\begin{tabular}{|c|c|c|}
\hline $\begin{array}{c}\text { Organización o } \\
\text { colectivo }\end{array}$ & Asuntos que los congrega & Actividades y modalidades de participación \\
\hline Polo Joven & 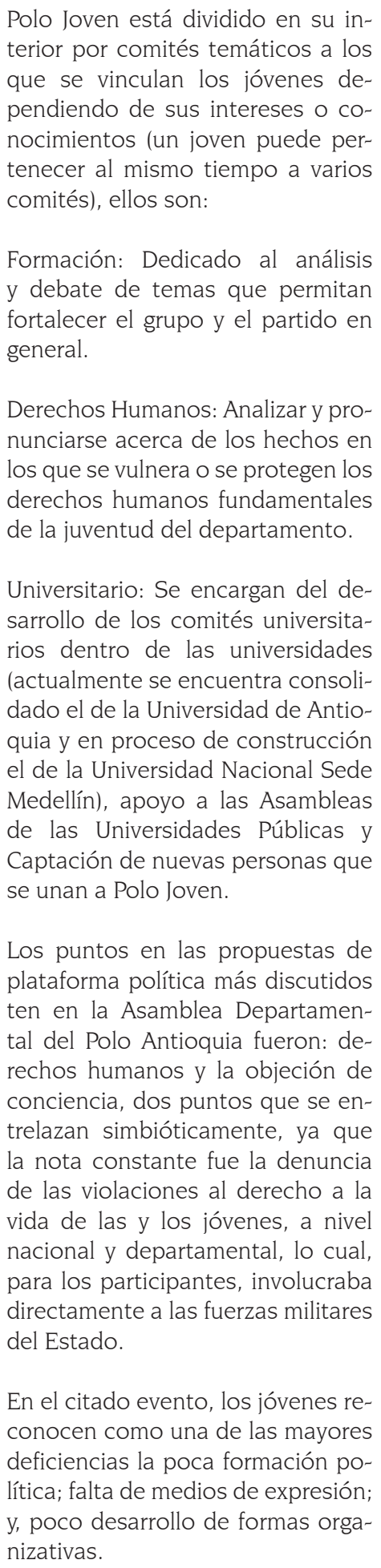 & $\begin{array}{l}\text { PROCESOS DE FORMACIÓN POLITICA: Conversatorios, debates } \\
\text { con precandidatos y foros en Universidades Públicas. } \\
\text { SEGUIMIENTO A TEMAS DE DERECHOS HUMANOS: Análisis de } \\
\text { situaciones que ocurren en la ciudad y el departamento que invo- } \\
\text { lucren la vulneración o protección de los derechos humanos de } \\
\text { los jóvenes, en la mayoría de ocasiones se generan pronuncia- } \\
\text { mientos posteriores a estos análisis. } \\
\text { PRONUNCIAMIENTOS PÚBLICOS: Acerca de temas analizados al } \\
\text { interior de los comités o debatidos por el pleno del colectivo, } \\
\text { también se realizan cuando se apoya o no una decisión del par- } \\
\text { tido o se acompaña en pleno a un candidato a cargos públicos. } \\
\text { BOLETINES INFORMATIVOS: Son un documento interno que } \\
\text { permite mostrarle al partido los avance, discusiones o decisiones } \\
\text { tomadas por un comité o por todo POLO JOVEN. } \\
\text { APOYO A PROCESOS ESTUDIANTILES: Asambleas y paros de es- } \\
\text { tudiantes de las Universidades públicas. } \\
\text { ASAMBLEA DEPARTAMENTAL DEL POLO JOVEN EN ANTIOOUIA: } \\
\text { En el marco de la contienda electoral (primera vuelta por la pre- } \\
\text { sidencia, Mayo 2010); los jóvenes, adscritos a Polo Joven, pero } \\
\text { también jóvenes sin filiación política que simpatizan con las } \\
\text { ideas de la izquierda apoyaron al candidato Petro, quien lidera } \\
\text { el ala de la izquierda democrática. En el desarrollo de las activi- } \\
\text { dades realizadas por el sector juvenil, la gran protagonista fue la } \\
\text { Tecnología y, de manera particular, las redes sociales. }\end{array}$ \\
\hline
\end{tabular}




\begin{tabular}{|c|c|c|}
\hline $\begin{array}{l}\text { Organización o } \\
\text { colectivo }\end{array}$ & Asuntos que los congrega & Actividades y modalidades de participación \\
\hline $\begin{array}{l}\text { Jóvenes } \\
\text { Verdes de } \\
\text { Colombia }\end{array}$ & $\begin{array}{l}\text { Defensa del medio ambiente; res- } \\
\text { peto a los derechos humanos; y, } \\
\text { todos los temas que se relacionan } \\
\text { con los principios de los jóvenes } \\
\text { verdes globales. En el contexto } \\
\text { de la coyuntura política colombia- } \\
\text { na, los jóvenes verdes apoyaron la } \\
\text { propuesta programática del candi- } \\
\text { dato Mockus, bajo el lema "Legali- } \\
\text { dad Democrática" Sin embargo, no } \\
\text { se puede olvidar que el apoyo de } \\
\text { jóvenes universitarios y de los jó- } \\
\text { venes fajardistas fue importante en } \\
\text { los resultados de la contienda elec- } \\
\text { toral y pueden existir diferencias } \\
\text { fundamentales entre unos y otros. }\end{array}$ & $\begin{array}{l}\text { Según información suministrada por jóvenes activistas del parti- } \\
\text { do Verde en Antioquia; y la información tomada del el blog Jóve- } \\
\text { nes Verdes de Colombia http://jovenesverdescolombia.blogspot. } \\
\text { com/2010_09_01_archive.html } \\
\text { El Partido Verde, desde las juventudes, ha venido participando, } \\
\text { trabajando y desempeñando un papel significativo en el Espa- } \\
\text { cio Coordinador de iniciativas por una participación activa en } \\
\text { la creación de la Plataforma Nacional de Juventud - JuventudEs } \\
\text { Colombia; espacio de diálogo, incidencia e interlocución de ca- } \\
\text { rácter transitorio, diverso, democrático, plural, autónomo e in- } \\
\text { cluyente de la sociedad juvenil hacia la construcción de la Plata- } \\
\text { forma Nacional de Juventud en Colombia. } \\
\text { A continuación se enuncian las prácticas y actividades que rea- } \\
\text { lizaron los Jóvenes Verdes de Antioquia en el marco de las dos } \\
\text { vueltas en la contienda electoral de } 2010 \text {. } \\
\text { Reuniones con jóvenes para identificar y contactar lideres univer- } \\
\text { sitarios y comunitarios; espacios de discusión sobre los } 15 \text { pun- } \\
\text { tos de la propuesta del partido; Club de amigos que se reunían } \\
\text { a ver los debates televisados; plan rumba (visita a las discotecas } \\
\text { a repartir publicidad); toma de puentes con afiches y recortes de } \\
\text { girasoles de los afiches oficiales; decoración de tenis y camise- } \\
\text { tas con los recortes de afiches; plan de recorrido por la ciudad: } \\
\text { hospitales, iglesias con el fin de permear espacios que no son de } \\
\text { naturaleza política; visitas a universidades y en las afueras can- } \\
\text { tos y consignas; Perform en centros comerciales; caravanas; plan } \\
\text { iglesias; flash mob. }\end{array}$ \\
\hline
\end{tabular}

\section{Conclusiones}

La indagación por los asuntos o temas que convocan a los y las jóvenes arroja más similitudes que diferencias entre las organizaciones juveniles partidarias. De esta manera, se puede afirmar que, los temas que convocan a los jóvenes son: las ideologías propias de cada partido al que está vinculada la organización de juventudes; asuntos de coyuntura política y económica; los derechos humanos; los temas ambientales; diversidad y equidad de género; necesidades de formación.

Aunque los jóvenes no lo explicitan, un punto en común que los congrega es la contienda electoral; pues, no obstante que en la mayoría de las veces los separa como colectividad porque se forman grupos de apoyo a candidatos específicos, particularmente en momentos de contiendas electorales para corporaciones Senado y Cámara; o para instancias departamentales o municipales; los momentos electorales elevan al máximo los niveles de actividad de los jóvenes en las respectivas organizaciones o colectivos.

En general, son muchas y variadas las actividades que realizan las organizaciones, colectivos y grupos partidistas; son también muchas las coincidencias que se aprecian entre las actividades de unas y otras. Así, por ejemplo: actividades de formación; de discusión; comunicados a la opinión; entre otras. En términos generales hay una fuerte tendencia de las organizaciones por realizar y por hacer saber la enorme cantidad de actividades que hacen; esto es lo que, en gran medida, les confiere el sentido de organización.

De todos modos, lo cierto es que se presenta una mayor innovación cuando se integran 
movimientos sociales a los partidos políticos; caso ilustrativo es lo que está ocurriendo en la organización de Juventudes Liberales con la incorporación del sector de jóvenes del movimiento "Poder Ciudadano". Otro caso similar se presenta con el movimiento "Corriente Democrática" que abandera el otrora candidato presidencial por el Polo Democrático, Gustavo Petro. Dicho movimiento está recargando baterías con la adhesión del movimiento social "Mentes de colores".

No obstante las similitudes que se advierten entre las cuatro organizaciones abordadas, es posible reconocer - en el marco de las prácticas de participación política- tres tendencias:

Una tendencia más tradicional e incluso más cercana a lo que hace y a los modos en que lo hace el partido o movimiento político; es el caso de las juventudes Liberales; Renovación Conservadora, y Juventudes de la U. En los tres casos, los congresos, las asambleas, los encuentros académicos, los debates sobre temas de actualidad, las actividades de formación y capacitación son lo dominante. Además, al parecer, quienes resultan beneficiados de los espacios de capacitación y formación son quienes coordinan o hacen parte del grupo o equipo de dirección o coordinación.

Una tendencia más próxima a los movimientos de izquierda, con alto contenido social e incluso con una fuerte inclinación y apoyo a las acciones de disidencia y de resistencia son aquellas que -caso Polo Joven y Poder Joven- proponen: acompañamientos a marchas por la diversidad o la defensa de los derechos humanos; seguimiento a temas de derechos humanos; acompañamiento a asambleas y marchas estudiantiles; apoyo a causas como "objetores por conciencia"; acciones por la paz y oposición a la militarización de la vida cotidiana. En esta tendencia se privilegian los argumentos y las razones que persuaden, que invitan a la acción por convicción; hay un mayor énfasis en el contenido por encima de la forma. La revolución está en la fuerza y en la claridad de las ideas. Es propio de esta tendencia el privilegio de actividades tales como: foros de discusión, comunicados que generen opinión; convocatoria o apoyo a marchas.

Una tendencia que resulta más proclive a las expresiones rituales, estéticas, culturales y artísticas, aquellas que tienden a trazar puentes entre la cultura y la política y viceversa. En esta tendencia, la relación intersubjetiva, pero también la relación de los sujetos con los objetos encierra enormes cargas simbólicas; las acciones se vuelven rituales, se le confiere un valor sagrado a la palabra; los objetos (lápiz, girasol, camisetas verdes) se entrelazan con los movimientos del cuerpo, con los gestos, con las consignas. Quienes se ubican en esta tendencia abogan por puestas en escena, performance en espacios públicos; tomas de lugares en los que no son habituales las prácticas políticas: iglesias, discotecas, puentes, centros comerciales.

El caso de la Ola Verde ilustra -de manera afortunada- esta modalidad de participación e intervención en política. La política habita la expresión artística, el gesto, el movimiento; la cultura se torna política, reclama la mirada del transeúnte, la presencia del ciudadano, del joven; la voz que se hace cántico, que se vuelve consigna, proclama; la política se torna cultura.

\section{Bibliografía}

Acosta V. Gladys y Garcés M. Ángela (2010). Ámbitos y escenarios de participación juvenil en Medellín. En: Revista Anagramas. Vol. 8 No.16, MedellínColombia, pp. 15-31.

Botero Gómez, Patricia y Torres Hincapié, Juliana (2008). Perspectivas Teóricas para comprender la categoría participación ciudadana-política juvenil en Colombia. En: Rev. Latinoamericana Ciencias Sociales Niñez y Juventud. 6 (2): 565-611. Disponible en: http://umanizales.edu.co/revistacinde/index.html Consultado 20.04.2010

Cárdenas Gracia, Jaime (2001). Partidos políticos y democracia. Cuadernos de Divulgación de la Cultura Democrática No.8. México, Instituto Federal Electoral. Cuaderno No. 8. Disponible en: G: $\backslash A L E D \backslash$ PROYECTO CIUDADANÍAS JUVENILES|PARTIDOS 
POLÍTICOS Y DEMOCRACIA.htm Consultado: 10.04.2010

Díaz Uribe, Eduardo (1986). Clientelismo en Colombia. Bogotá: El Áncora Editores.

Duque Daza, Javier (2007). Los partidos políticos colombianos 1974-2006: subinstitucionalización de los partidos tradicionales y emergencia de organizaciones políticas alternativas. Informe final del concurso: Partidos, movimientos y alternativas políticas en América Latina y el Caribe. Programa Regional de Becas CLACSO. Disponible en: http://bibliotecavirtual.clacso.org.ar/libros/becas/ semi/2004/partidos/duque.pdf Consultado: 3.12.09

Giraldo García, Fernando (2003). Sistema de partidos políticos en Colombia. Estado del arte. 1991-2002. Bogotá: Centro Editorial Javeriano, Ceja.

INFORME DE LA CEPAL (2004). La juventud en Latinoamérica tendencias y urgencias. Capítulo viii participación y ciudadanías. Santiago de Chile, pp. 267 -288.

MOUFFE, Chantal (1999). El retorno de lo político. Comunidad, ciudadanía, pluralismo, democracia radical. Barcelona: Paidós.

(2007). En torno a lo político. México: Fondo de Cultura Económica.

Parra Ramírez, Esther (1999). Vicisitudes del bipartidismo en Colombia. En: Revista Reflexión Política, Año 1 No. 1. Bucaramanga, pp. 54-76. Disponible en: http://editorial.unab.edu.co/revistas/reflexion/pdfs/ dem_11_2_c.htm. Consultado: 16.06.10.

Pérez, Héster (1989). Proceso del bipartidismo colombiano. Bogotá: Editorial Universidad Nacional.

REGUILLO CRUZ, Rossana (2000). Emergencia de Culturas Juveniles. Estrategias del Desencanto. Buenos aires: Grupo Editorial Norma.

(2003). Ciudadanías Juveniles en América Latina. Última Década, No.19. Viña del Mar: Ediciones CIDPA.

ROLL, David. Rojo difuso y azul Pálido (2002). Los partidos políticos tradicionales en Colombia: entre el debilitamiento y la persistencia. Colombia: Universidad Nacional de Colombia. Facultad de Derecho, Ciencias Políticas y Sociales.
URRESTI, Marcelo (2000). Paradigmas de la participación juvenil: un balance histórico. En: En publicación: La participación social y política de los jóvenes en el horizonte del nuevo siglo. Sergio Balardini. CLACSO, Consejo Latinoamericano de Ciencias Sociales, Ciudad Autónoma de Buenos Aires, Argentina. ISBN: 950-9231-55-x. Fecha de consulta: Abril 2009. Acceso al texto completo: http://bibliotecavirtual. clacso.org.ar/ar/libros/cyg/juventud/sandoval.pdf Consultado: 10.07.2010.

VALENZUELA FUENTES, Katia (2007). Colectivos juveniles: cinmadurez política o afirmación de otras políticas posibles. En: Revista Última Década, Número 26. Cidpa, Valparaíso.

\section{Páginas Web consultadas.}

http://www.colombiademocratica.com/index. php?option $=$ com contentEtask $=$ viewEid $=17 E \mathrm{I}$ temid=31 Fecha de consulta: 12/10/2010

http://www.elpartidodelau.com/index.php?p=3Eite =1 Fecha de consulta, 08/11/2010

http://www.partidocambioradical.org/nosotros.html Fecha de consulta: 24/10/2010

http://www.polodemocratico.net/ Fecha de consulta16/09/2010

http://www.partidoverde.org.co/HistoriaPartidoVerde. aspx Fecha de consulta 16/09/2010

http://jovenesverdescolombia.blogspot.com/2009/10/ partido-verde.html Fecha de consulta 02/10/2010

http://www.facebook.com/search.php?q= partido + ve rdeEinit $=$ spellEtas $=0.2905277820435005 \varepsilon \mathrm{ref}=$ ts\#!/group.php?gid = 112563175438355 Fecha de consulta 15/10/2010

Entrevistas a jóvenes miembros activistas de las tres organizaciones de juventud partidista (Juventudes Liberales; Renovación Conservadora; Polo Joven) y del colectivo (Jóvenes Verdes de Antioquia).

La información de base es tomada de: http://www. partidocambioradical.org/nosotros.html 